\title{
A ESCOLA PÚBLICA E O IMAGINÁRIO DE INCLUSÃO DIGITAL: OS DISCURSOS SOBRE O SUJEITO-ALUNO NO MERCADO DE TRABALHO
}

\section{THE PUBLIC SCHOOL AND THE IMAGINARY OF DIGITAL INCLUSION: THE DISCUSSIONS ON THE SUBJECT-STUDENT IN THE LABOR MARKET}

\author{
Cristiane Pereira dos Santos ${ }^{1}$ \\ Ana Maria Di Renzo ${ }^{2}$ \\ Universidade do Estado de Mato Grosso
}

\begin{abstract}
RESUMO
Este trabalho pretende refletir pelo viés da Análise de Discurso de Linha Francesa, as discursividades sobre o sujeito-aluno na era digital e o imaginário de formação deste sujeito para o mercado de trabalho. Para tanto, foram selecionados dois programas de governo que objetivam levar à Escola Pública a inclusão digital - Educação Digital: política para computadores e tablets (2012) e Programa Nacional de Tecnologia Educacional (1997). Na discursividade do Estado, essas políticas públicas de inclusão digital estão funcionando pela ideologia capitalista e neoliberal de Estado, atravessando assim, as instituições escolares, as atividades de linguagens entre os professores e, principalmente, os alunos.
\end{abstract}

PALAVRAS-CHAVE: Sujeito-aluno; Análise de Discurso; Mercado de trabalho.

\begin{abstract}
This paper aims to reflect the bias of French Discourse Analysis, the discourses on the subject student in the digital age and the imagination of formation of this subject for the labor market. To this end, we selected two government programs that aim to bring the public school digital inclusion - Digital Education: policy for computers and tablets (2012) and the National Educational Technology Program (1997). In the discourse of the state, those policies of digital inclusion are working for the capitalist and neo-liberal ideology of state, through well, educational institutions, the activities of languages among teachers and especially the students.
\end{abstract}

KEYWORDS: Subject student; Discourse Analysis; Job market.

\section{INTRODUÇÃO}

Pensar a escola pública, em especial, faz-nos pensar a construção de um Estado brasileiro que oferece ensino àqueles por muito tempo marginalizados e esquecidos. Há de se considerar a complexa história de colonização, pela qual passou o Estado brasileiro e, em decorrência, os modos de se fazer educação.

Desse modo, para compreendermos os sentidos de "escola" em funcionamento em nosso material de análise, isto é, o Programa Nacional de Tecnologia Educacional - ProInfo (1997 e

\footnotetext{
${ }^{1}$ Mestre em Linguística pelo Programa Stricto Senso em Linguística da Unemat, email: cris_tanynha@hotmail.com

2 Doutora em Linguística pela Universidade Estadual de Campinas, email: arenzo@unemat.br
} 
reformulado em 2007) e o Programa Educação Digital: política para computadores e tablets (2012), faz-se necessário lançarmos um olhar para a história da educação praticada no Brasil. No entanto, não objetivamos fazer uma história da educação brasileira, mas buscar pontos importantes nessa história já constituída em diferentes condições de produção que nos auxiliem a compreender o modo de funcionamento da Escola no Brasil, posto que "a Escola não só significa pelas suas políticas, mas pelas condições nas quais elas se sustentam (DI RENZO, 2007, p.36).

\section{Breve contextualização da história da educação brasileira}

Com a chegada dos primeiros padres jesuítas, inaugurou-se uma fase que deixou muitas marcas na história da escolarização brasileira. Em nosso entendimento, passarmos por esses momentos marcantes faz-se necessário para a compreensão da forma sujeito brasileira. É necessário entendermos que o sujeito para a Análise de Discurso é o resultado da relação entre a linguagem e história, cuja forma de assujeitamento se dá pela ideologia quando o indivíduo é por ela interpelado em sujeito. Assim, "não há discurso sem sujeito, nem sujeito sem ideologia" (ORLANDI, 2010, p.11).

A vinda dos portugueses ao Novo Mundo e, por conseguinte, a dos padres jesuítas, trouxe um padrão de educação próprio da Europa. Portanto, os jesuítas não trouxeram apenas a religiosidade e costumes europeus, mas trouxeram também métodos educacionais próprios.

No século XVI, no Brasil, como diz Silva (1998),

não havia economia mercantil, não havia burguesia, não havia cidades, não havia trabalhador livre, não havia língua nacional, não havia imprensa, não havia livros, mas... havia escola de ler, escrever e contar, pois havia, sobretudo, um mundo a explorar, a pacificar, a controlar, a administrar para possibilitar a expansão e o fortalecimento da economia mercantil. Aqui, a passagem da oralidade para escrita foi de uma outra natureza e teve outras funções sociais, políticas e culturais (SILVA, 1998, p.199).

Com a vinda do branco para terras indígenas, deu-se início a um processo de escolarização no qual estavam calcados os seguintes objetivos: ensinar uma nova língua, converter o povo "feroz" em povo um "civilizado" e catequizá-los, restando, ainda assim, outro grande problema: quem deveria ou não ir para as primeiras escolas ou quem deveria aprender a língua do colonizador, originando-se, a partir daí, o primeiro processo de exclusão.

Um longo e amplo trabalho com as línguas indígenas se inicia, bem como o processo de elaboração de cartilhas, sermões, traduções; assim, buscava um saber "sobre" essas novas línguas com produção de dicionários e gramáticas, a fim de estabelecer uma comunicação que possibilitasse a catequese e a constituição de um novo universo por meio da oralidade e da escrita.

De acordo com Silva (2006, p.136), "o discurso da escolarização no Brasil é determinado pela formação discursiva religiosa-cristã-católica, dominada pela formação ideológica da colonização". Nesse sentido, a forma-sujeito, aqui constituída, caracteriza-se pela forma sujeito religioso, haja vista que o principal interesse do colonizador não era ensinar a ler, escrever, mas catequizar os índios e os demais por meio do discurso religioso, para dessa maneira mostrar o seu lugar naquele espaço, e mostrar que sua doutrina deveria ser seguida. Ainda seguindo os estudos de Silva (2006, p. 61), "todos deveriam ser, senão instruídos, aculturados segundo a moral branca europeia, cristã-católica, institucionalmente, uma aculturação mediada pela letra e pela escrita".

Com a imposição de uma cultura, de uma língua e de uma religião, os jesuítas dominaram o campo do conhecimento por praticamente três séculos. Segundo Nunes (2000, p.39), "com a expulsão dos jesuítas pelo Marques de Pombal, o ensino secundário passou a ser oferecido em aulas isoladas ou avulsas em todas as províncias, pelo menos até a regência, salvo raras iniciativas". A partir desse momento, torna-se necessária uma educação própria do Brasil, voltada para um processo econômico-social advindo da escravidão que cada vez mais ganhava força. 
Nesse momento histórico para a educação, era necessário

[...] pacificar o espaço social, controlar as pulsões, as emoções e os afetos, para se obter uma colonização eficaz em termos de riqueza para o reino de Portugal e de almas convertidas para o reino de Deus. Era preciso implantar e difundir na nova terra, as proibições, as censuras e os mecanismos de controle, em lugar e tempo próprios, a maneira de ser e de agir dos homens de um outro mundo: o europeu-branco-cristão/católico (SILVA, 1998, p.199).

A situação da educação brasileira, nesse momento, ainda era uma das piores, pois "não havia escolas técnicas nem superiores, e principalmente, a imprensa era proibida, pois além de não se imprimirem livros no Brasil, era extremamente difícil obtê-los vindos do estrangeiro" (BARBOZA VAZ, 2005, p.35). De acordo com Ribeiro (1998), o modelo educacional continuou a ser copiado de países europeus,

Para maior garantia, aqueles que tinham interesse e condições de cursar o ensino superior deveriam continuar enfrentando os riscos das viagens e frequentar a Universidade de Coimbra reformada e/ou outros centros europeus. Assim, fica evidenciado que as Reformas Pombalinas visavam transformar Portugal numa metrópole capitalista [...]. Visavam, também, provocar algumas mudanças no Brasil, com o objetivo de adaptá-lo, enquanto colônia, à nova ordem pretendida em Portugal (p.35).

Como vimos, a educação ainda era para poucos, isto é, era acessível apenas para a sociedade elitizada. Essa situação só começou a ser mudada em 1808 com a vinda de Dom João VI para o Brasil. De acordo com Barboza (2005), a estada do Rei em terras brasileiras seria bastante longa, "portanto, além de abrir os portos do Brasil às nações amigas, resolveu permitir a imprensa, facilitar a entrada de livros e fundar cerca de uma dezena de instituições de ensino técnico ou superior em todo território, no Rio de Janeiro e na Bahia" (p. 38). Com isso, houve no sistema educacional a unificação dos métodos de ensino com a finalidade de que a formação do sujeito-aluno pudesse ser única, possibilitando que houvesse um crescimento no sistema educacional. Mas, apesar desses avanços no setor da educação e tantos outros na economia e na política, a sociedade almejava a independência do País.

Com a instalação do Regime Republicano, a expansão econômica e o novo modelo jurídico instalado, exigiu-se outra categoria de sujeito - o sujeito de direito. Nesse novo espaço, nascia outro tipo de organização social: o assalariado com direitos e deveres, submetido livremente a um contrato de trabalho urbano. Construir um Estado nacional forte também significava construir uma língua nacional que pudesse ser ensinada para todos, por meio de um processo de escolarização assumido pelo Estado a partir de uma de suas principais instituições: a Escola que passava reconhecidamente como a grande ferramenta para o progresso de um país.

A Primeira República (1889-1930), reconhecida por sua grande exportação de café, foi cedendo espaço aos poucos a grupos militares e empresários industriais, pois a economia se voltava para o mercado interno e para a industrialização, ainda que com uma velocidade muito lenta. $\mathrm{O}$ grande marco dessa passagem foi, sem dúvida nenhuma, o Governo Provisório de Getúlio Vargas, governo de caráter populista e hábil que conquistou grande parte da sociedade.

A Primeira República (1889-1930), reconhecida por sua grande exportação de café, foi cedendo espaço aos poucos a grupos militares e empresários industriais, pois a economia se voltava para o mercado interno e para a industrialização, ainda que com uma velocidade muito lenta. $\mathrm{O}$ grande marco dessa passagem foi, sem dúvida nenhuma, o Governo Provisório de Getúlio Vargas, governo de caráter populista e hábil que conquistou grande parte da sociedade.

De acordo com Andreotti (2011, p. 02), “a educação escolarizada que se estruturou após 1930 já se anunciava com a República, na qual um projeto de escolarização se organizava, tendo em vista a inserção de parte da população que se encontrava a margem do processo político 
republicano". Efeitos de sentidos decorrentes dessas afirmações, segundo a autora, "a escola como um projeto de ascensão e inserção social era um valor já consubstanciado no fim do século XIX, no limiar da República” (p.01).

O cenário do País e da própria educação passa por um grande conflito com a queda do Estado Novo, ocorrido em 1945, gerando um período de conflitos e mudanças, pois acabava de terminar a $2^{\text {a }}$ Guerra Mundial, instalando a fragilidade nos/entre os países que buscavam se reconstruir.

No Governo de Juscelino Kubitschek (1945-1964), um grande passo para a educação foi dado com a Constituição da República promulgada em 18 de setembro de 1946, característica das democracias em vigor e pautada em princípios liberais. Assim, a política educacional do período de 1947 a 1961 se voltou para discussões em torno de uma Lei de Diretrizes e Bases da Educação Nacional (LDB), que norteou todos os níveis de ensino do território nacional e estabeleceu, entre outros, os fins para a Educação:

Art. $1^{\circ}$ A educação nacional, inspirada nos princípios de liberdade e nos ideais de solidariedade humana, tem por fim:

a) a compreensão dos direitos e deveres da pessoa bumana, do cidadão, do Estado, da família e dos demais grupos que compõem a comunidade;

b) o respeito à dignidade e às liberdades fundamentais do homem;

c) o fortalecimento da unidade nacional e da solidariedade internacional;

d) o desenvolvimento integral da personalidade humana e a sua participação na obra do bem comum;

e) o preparo do indivíduo e da sociedade para o dominio dos recursos científicos e tecnológicos que lhes permitam utilizar as possibilidades e vencer as dificuldades do meio;

f) a preservação e expansão do patrimônio cultural;

g) a condenação a qualquer tratamento desigual por motivo de convicção filosófica;

O termo "liberdade" é mencionado diversas vezes como um princípio sem, no entanto, referir-se a que tipo de liberdade está se referindo. Desse modo, a palavra "liberdade" desliza para o discurso de que "todos somos iguais", um princípio de igualdade regido pelo Estado que coloca a Escola no consenso de que "é preciso "incluir" para gerar a igualdade" (DIAS, 2010, p.50). Nessa discursividade sobre igualdade e direito dos cidadãos na sociedade dita democrática, Araújo (2011), afirma que,

a democracia contemporânea se sustenta na justiça e na articulação entre a igualdade entre todos os seres humanos e a equidade, que reconhece o princípio da diferença dentro da igualdade. Se pensamos a democracia somente a partir do ideal de igualdade, acabamos por destruir a liberdade. Se todos forem concebidos como iguais, onde fica o direito democrático da diferença, a possibilidade de pensar de maneira diferente e de ser diferente? Para que o modelo de democracia seja justo e almeje a liberdade individual e coletiva, é necessário que a igualdade e a equidade sejam compreendidas como complementares. Ao mesmo tempo que a igualdade de direitos e deveres deve ser objetivada nas instituições sociais, não se deve perder de vista o direito e o respeito à diversidade, ao pensamento divergente (p.36, grifos do autor).

Tratar os desiguais de forma igual é um efeito de sentido produzido pela contradição. Assim, entendemos a contradição conforme aponta Foucault (1995),

O discurso é o caminho de uma contradição a outra: se dá lugar às que vemos, é que obedece à oculta. Analisar o discurso é fazer com que desapareçam e reapareçam as contradições; é mostrar o jogo que nele elas desempenham; é 
manifestar como ele pode exprimi-las, dar-lhes corpo, ou emprestar-lhes uma fugidia aparência (FERNANDES, 2012, p. 42).

Trabalhando com o conceito de contradição proposto por Foucault no que diz respeito à formação do sujeito para o uso das tecnologias proposta pela LDB/61, materializado pelo "preparo do indivíduo e da sociedade para o domínio dos recursos científicos e tecnológicos que lhes permitam utilizar as possibilidades e vencer as dificuldades do meio", temos um fato linguístico: a inclusão das novas tecnologias visa a preparar o indivíduo para o uso de novos recursos tecnológicos como condição de "vencer as dificuldades do meio". Uma discursividade que se marca pela política do "dominar as novas ferramentas", especialmente para melhorar a produtividade.

Desse modo, o termo "domínio", usado nas discursividades da LDB/61, num jogo parafrástico, desliza para sentidos como competências e habilidades para o uso das novas ferramentas tecnológicas, que, no discurso do Estado, são disponibilizados na Escola por meio do ProInfo e do Programa Educação Digital. Assim, dominar as ferramentas digitais seria a solução para a melhoria da aprendizagem que o Estado oferece por meio do ensino público. Nos dizeres desses programas, dominar as novas tecnologias é estar incluído digitalmente e na sociedade capitalista.

No discurso da LDB/61, "vencer as dificuldades do meio" desliza para "vencer as dificuldades do mercado de trabalho", "vencer outros concorrentes que estão mais bem qualificados", "disputar uma vaga no mercado de trabalho", dando visibilidade ao discurso da qualificação para as TICs voltada para um engajamento profissional. Não importa saber, ter conhecimento, o sujeito tem apenas que saber usar as ferramentas digitais, isto é, estar qualificado tecnologicamente. De acordo com o dicionário Aurélio (2006), o termo "qualificar" significa, "1 Indicar a (s) qualidade (s)de avaliar. 2 Avaliar, apreciar. 3 Considerar habilitado, apto, idônio. 4 Atribuir qualidade (s) a. 5 Classificar". Entretanto, para a LDB/6, é dominar recursos para adaptarse aos meios. Já, para Orlandi (2014, p. 147), a qualificação está voltada especialmente para o mercado de trabalho, pois, segundo ela, "o denominador comum é o trabalho e não o conhecimento. Sentidos que nos levam a compreender que fica silenciado, na discursividade da LBD/6, a qualificação dos sujeitos-alunos. Assim, com a entrada das novas tecnologias na Escola, o Estado não visa a modernização desse ambiente apenas para ajudar os que estão à margem da sociedade, os sentidos outros nesses discursos dizem sobre os benefícios que esses sujeitos podem oferecer para a economia, isto é, para os principais setores produtivos do País.

Diante da necessidade de modernização da sociedade e da Escola, na década de 1960, foi realizada a primeira conferência das Nações Unidas sobre Informática. Momento em que as tecnologias de informação e comunicação começavam a exercer papel importante no desenvolvimento econômico e social na sociedade. Nos anos 70 e 80, vários países começavam a receber planos e programas para a capacitação tecnológica, porém o Brasil, apenas no final da década de 90, lança o Programa Nacional de Tecnologia Educacional que leva às Escolas públicas de todo o País os laboratórios de informática com a garantia de acesso à internet para regiões mais afastadas dos grandes centros.

Olhar para a história da educação nos permite historicizar mudanças, transformações históricas, ideológicas, culturais e econômicas. Segundo Saviani (2008, s/p) 3 , "ao longo de quase quatro séculos abarcando, portanto, os quatro primeiros períodos, as instituições escolares no Brasil constituíram um fenômeno restrito a pequenos grupos", primeiramente pela dominação dos colégios pelos padres jesuítas; depois pelo período representado pela reforma pombalina e a primeira tentativa de instaurar a escola pública; por outro período que se caracteriza principalmente pela tentativa de colocar a escola como responsabilidade do poder público representado pelo governo imperial; e, por fim, quando nascem as primeiras escolas primárias em forma de grupos

\footnotetext{
${ }^{3}$ Conferência de abertura do V Colóquio de Pesquisa sobre Instituições Escolares, organizado pela Uninove e realizado
} em São Paulo, de 27 a 29 de agosto de 2008. 
escolares. Nesse sentido, após quatro séculos, é que a Escola passa a receber um número maior de alunos, mas que não se ocupa em lidar com suas consequências. Cury (2008, p. 119) aponta que, com a Constituição de 1988,

a educação se torna o primeiro dos direitos sociais (art. $6^{\circ}$.), o ensino fundamental, gratuito e obrigatório, ganha a condição de direito público subjetivo para todos, os sistemas de ensino passam a coexistir em regime de colaboração recíproca, a gestão democrática torna-se princípio dos sistemas públicos de ensino e a gratuidade, em nível nacional e para todos os níveis e etapas da escolarização pública, torna-se princípio de toda a educação nacional (p. 205214).

A escola funciona imaginariamente no discurso da "integração social" (ORLANDI, 2002, p.254), imaginário também que coloca a inserção das novas tecnologias de informação e comunicação na Escola como uma forma de salvação para a educação e de igualdade de acesso às novas ferramentas.

\section{A escola pública e o discurso da inclusão digital: preparando o sujeito-aluno para o mercado de trabalho}

Como analistas de discurso, pretendemos dar visibilidade a esses sentidos da história da educação praticada no brasil desde a colonização até os dias atuais a fim de desestabilizá-los e compreendermos quais os efeitos de sentido no modos operandi de se fazer política pública, em nosso caso, políticas que levem à Escola pública novas ferramentas digitais. Para tanto passaremos para as análises de nossos corpus.

As discursividades que constituem no ProInfo o concebem como um facilitador para a melhoria da qualidade do processo de ensino-aprendizagem:

Qualidade educacional pressupõe introdução de melhorias no processo de construção do conbecimento, busca de estratégias mais adequadas à producão de conhecimento atualizado e desenvolvimento no educando da habilidade de gerar conhecimento novo ao longo da vida. Implica diversificar espaços do conhecimento, processos e metodologias.

É uma qualidade comprometida com a eqüidade, e, por isto, com a tentativa de - numa sociedade cada vez mais tecnologicamente evoluída - oportunizar a todos:

a igualdade de acesso a instrumentos tecnológicos disponibilizadores e gerenciadores de informação;

os beneficios decorrentes do uso da tecnologia para desenvolvimento de atividades apropriadas de aprendizagem e para aperfeiçoamento dos modelos de gestão escolar construidos em nivel local, partindo de cada realidade, de cada contexto (Diretrizes, 1997, p.03, grifos nossos).

Ao propor que a melhoria da qualidade de ensino-aprendizagem pressupõe e implica outros/novos processos e metodologias, cria-se o imaginário de que as TICs é a melhor metodologia. Nesse sentido, busca estratégias mais adequadas à produção de conbecimento atualizado; marca uma posição: é a tecnologia quem gera o saber. Logo, nas discursividades do ProInfo se o professor não está atualizado para o uso das ferramentas, não dispõe de saber. Assim, a melhoria da qualidade de ensino está filiada à memória discursiva do sistema capitalista, que coloca a Escola na esfera do desenvolvimento científico e tecnológico para avançar os meios de produção.

A discursividade da igualdade de acesso materializa o discurso da inclusão social dos menos favorecidos às novas ferramentas tecnológicas, combatendo à injustiça social, apagando assim toda uma história de desigualdade. Dominar os recursos é sair da margem, é um efeito discursivo e não realidade, ainda que seja só para reproduzir o já produzido. Nesse sentido, a política de inclusão digital oferece a esses sujeitos segregados pelo sistema capitalista a possibilidade de fazer parte da sociedade. Nessa discursividade do novo em nossa sociedade, afirma Dias (2010), 
Ter conhecimento de informática passa, portanto, a fazer parte fundamental do princípio identificatório valorizante da sociedade da informação. O aprendizado da informática é a motivação desse sujeito para sair de um lugar de nãoreconhecimento, de isolamento de pobreza, de desemprego. Sem esse conhecimento o sujeito é relegado à 'inutilidade', ele está fora do jogo (p.66).

Estar no jogo/jogar o jogo é condição da sociedade capitalista, pois estar fora do mundo digital é se colocar fora das condições de produção do mercado de trabalho, que busca cada vez mais profissionais que saibam manusear máquinas, resolver problemas com facilidade, enfim, trabalharem diretamente com a rede mundial de computador. Com essas novas exigências, a Escola mais uma vez é tomada como o aparelho do Estado para consolidar a sociedade que se espera.

A mesma regularidade de sentido pode ser vista em relação à qualidade do ensino como uma das prioridades máximas do ProInfo:

Programa abrangerá a rede pública de ensino de $1^{\circ}$ e $2^{\circ}$ graus de todas as unidades da federação. Para o biênio 97/98, está prevista a aquisição de 100.000 computadores, cuja instalação nas escolas respeitará critérios acordados entre a SEED/MEC e as Secretarias Estaduais da Educação - SEE. Deverão ser beneficiadas, nesta primeira etapa (97-98) do Programa Nacional de Informática na Educação, cerca de 6 mil escolas, que correspondem, por exemplo a 13,40\% do universo de 44,8 mil escolas públicas brasileiras de $1^{\circ}$ e $2^{\circ}$ graus com mais de cento e cinquenta alunos. Considerando-se utilização em três turnos, dois alunos por máquina e dois períodos de aula por semana, será possivel, durante o periodo letivo, atender a 66 alunos por máquina. Nesta estimativa não está sendo levada em consideração a utilização dos computadores - que, naturalmente não deverá corresponder à realidade - durante os quatro meses de férias escolares (por alunos ou membros da comunidade) (Diretrizes, 1997, p.03, grifos nossos).

Podemos dizer que a abrangência do programa se dá pelos pressupostos de que todos devem estar conectados, materializados no discurso do programa no seguinte tripé: qualidade do ensino, inserção de tecnologia e igualdade de acesso. Quando se diz que o programa abrangerá todas as unidades da federação, entende-se que o programa será levado a todas as escolas. No entanto, há etapas: a primeira com a abrangência de 6 mil escolas públicas, o que não significa dizer que todos os alunos serão beneficiados.

De acordo com Orlandi (2008) os efeitos da ideologia produzem a aparência da unidade do sujeito e um falso efeito de transparência do sentido. "Estes efeitos, por sua vez, funcionam como 'evidentes' que, na realidade, são produzidos pela ideologia”. Mas é necessário levar em consideração dois pontos principais: "a) o processo de constituição do sujeito; e b) a materialidade do sentido" (p.56). Essa constituição do sujeito e da materialidade do sentido, a nosso ver, nos ajuda a compreender que os discursos das TICs unificam os sujeitos pelo discurso da inclusão digital, como uma política pública, porém, o falso efeito de transparência se dá pelo discurso da qualidade de ensino.

Ao afirmar que atenderá apenas $13,40 \%$ do universo de 44,8 mil escolas públicas, dá-se visibilidade ao tratamento desigual dos excluídos. Se levarmos em consideração a quantidade de crianças e jovens fora da escola, seja por condições sociais ou geográficas, flagraremos a contradição pelo equívoco. A língua é lugar de falha e significa o silenciado. Dizer que apenas a universalização de acesso às tecnologias será suficiente para garantir uma melhor qualidade de ensino e uma Escola atrativa faz parte de um discurso falacioso quando se relaciona rendimento escolar com as condições socioeconômicas.

De acordo com dados do professor Leonardo Mendes ${ }^{4}$, se o Brasil não adotar medidas de acesso/universalização às novas tecnologias de informação e comunicação em todas as escolas

\footnotetext{
${ }^{4}$ Professor do departamento de comunicação da Faculdade de Engenharia Elétrica da Unicamp.
} 
públicas, é possível que o País perca um valor muito alto no PIB. Essa perda "pode representar algo da ordem dos U\$\$ 100 bilhões por ano de atraso" (MENDES, 2008, p.34). Assim, esse é um argumento forte para que o Estado ofereça à população o acesso à rede mundial de computadores. Tanto é que, no ano de 2007, o programa, por meio do Decreto 6.300, passa por reformulação e novamente se destaca a importância de "fomentar a melhoria do processo de ensino e aprendizagem com o uso das tecnologias de informação e comunicação" (Decreto Presidencial no 6300/2007, grifos nossos). Podemos dizer que a inclusão digital e melhoria da aprendizagem estão diretamente ligados na discursividade do Estado.

O verbo fomentar tem origem na palavra "fomento" (do Latim fomentum), que significa "aquecer", estimular a criação de novas políticas para impulsionar o progresso de algo, nesse caso, das novas tecnologias de informação e comunicação.

Nos discursos seguintes do Ministro da Educação, a Escola prepara o País para o futuro, materializado pela inserção das novas ferramentas tecnológicas. Em entrevista ao programa "Bom dia, Ministro" (2012), o Ministro Aloízio Mercadante comenta sobre a importância da distribuição de tablets aos professores das escolas públicas brasileiras. É importante destacar que o programa acontece semanalmente e, são realizadas entrevistas com ministros de Estado. O programa é produzido e coordenado pela Secretaria de Comunicação Social da Presidência da República em parceria com a EBC Serviços. Nessa entrevista, concedida no mês de março de 2012, o ministro afirma:

A escola tem que preparar o Brasil para o futuro, e a escola tem que dar direitos iguais. Então, essa geração tem que ter acesso às novas tecnologias na sala de aula. Eu vou brigar por isso. Nós estamos, cada vez, articulando mais com o Ministério da Ciência, Tecnologia e Inovação e com o Ministério da Educação (ENTREVISTA com o Ministro da Educação no "Bom dia Ministro" grifos nossos).

Compreendemos que os sentidos em circulação no discurso do ministro reafirmam a Escola como responsável pela transformação da sociedade por meio da inclusão digital, dando aos professores direitos iguais. $\mathrm{O}$ verbo ter $(\mathrm{tem})$ no presente do indicativo presentifica o comando do Estado que vê nas TICS a Escola do futuro. Assim, perguntamo-nos: as TICs nas Escolas públicas são capazes de acabar com as desigualdades? Ao mesmo tempo em que o ministro imputa a responsabilidade para a instituição, apresenta-se como guerreiro: "vou brigar por isso". Brigar não é garantir direitos iguais, posto que ele está na posição de chefe de Estado.

Dando sequência à mesma entrevista, o Ministro volta a falar sobre a distribuição de tablets para os professores da rede pública:

A escola tem que se preparar para o futuro, tem que ser a grande porta de entrada, principalmente para as crianças pobres, porque elas só terão chance de entrar no mundo da internet através da escola. E se elas entrarem nesse mundo, nós vamos descobrir talentos e profissionais competentes para o futuro (Discurso do Ministro da Educação Aloízio Mercadante, grifos nossos).

Orlandi (2014, p. 143), ao analisar o slogan do governo de Dilma Rousseff: "País rico épaís sem pobreza", mostra que esse bordão poderia ser substituído por "País rico épaís educado". Desse modo, "O que é um país educado? A autora destaca que o governo não sabe ou não procura saber, pois esta resposta dá como consensual: todo mundo “"sabe” o que é um país educado”. Assim, o que entra em jogo é

o efeito de sentido que aí se produz, por ilação, é que 'país sem pobreza é país educado'. O que nos leva a concluir que a educação erradica a pobreza. Ou, o que se dá, na ideologia consensual, a de a que nossa riqueza é a educação. Posta em um enunciado repetido à exaustão em países em que a educação é um bem de consumo caro: 'A melhor herança é um diploma'. Quem não o tem é segregado do 'desenvolvimento social', ou seja, fica fora da formação social (ORLANDI, 2014, p. 144, grifos da autora). 
A ideologia neoliberal, que perpetua na sociedade contemporânea, inscreve a Escola no imaginário do desejo de muitos e na necessidade de melhoria das condições sociais, uma vez que estar nela é estar inserido no "desenvolvimento social", e quem está fora é segregado dessa condição social. O discurso "proporcionar um futuro melhor para as crianças pobres" se sustenta nesta ideologia consensual de que a melhor saída para deixar de ser pobre é a educação, isto é, a maior riqueza agora é fazer uso das TICs na Escola. E essas são capazes de descobrir profissionais competentes. Novamente não interessa saber, é preciso saber usar. Mas a grande questão que fica silenciada, segundo Orlandi (2014, p.145), é "como dar condições para educar, para ir à escola, para quem não tem os meios necessários? $?^{5}$ Mais do que isso: sem a posse de bens sociais mínimos, já se está fora dos que contam nesta sociedade”. Em outras palavras, os excluídos continuam sendo excluídos, porque se oferecem políticas iguais para sujeitos desiguais.

Essas discursividades, que envolvem a melhoria da qualidade de ensino, universalização das novas tecnologias no ambiente escolar e diminuição das diferenças sociais aparecem mais uma vez nas Diretriz̧es do ProInfo. Na formulação "possibilitará criação de uma nova ecologia cognitiva nos ambientes escolares mediante incorporação adequada das novas tecnologias da informação pelas escolas", ou seja, a nova ecologia da aprendizagem se faz pela incorporação adequada. Salientamos que incorporar não convoca nenhuma ação a não ser a de se adaptar. Observamos, assim, que, não se alteram as concepções de ensino e aprendizagem do conhecimento. Apenas são adaptadas às novas ferramentas. Analisemos outras formulações.

É preciso diminuir a lacuna existente entre a cultura escolar e o mundo ao seu redor, aproximar a escola da vida, expandindo-a em direção à comunidade e tornando-a facilitadora das interações entre os atores humanos, biológicos e técnicos. Esse novo meio ecológico é composto pelas mentes humanas e as redes técnicas de armazenamento, transformação, produção e transmissão de informações. Para a criação dessa nova ecologia é importante que o professor encare os elementos do contexto em que vive o aluno e as incorpore no cotidiano da escola, criando, assim, um novo ambiente semelhante à vida, ao que o aprendiz encontrará nas atividades sociais, nos serviços e nas organizações.

O desenvolvimento das estruturas mentais é influenciado pela cultura, pela linguagem usada pela coletividade e pelas técnicas de produção, armazenamento e transmissão das representações da informação e do saber. Por isto, as novas tecnologias da informação devem ser aproveitadas pela educação para preparar o novo cidadão, aquele que deverá colaborar na criação de um novo modelo de sociedade, em que os recursos tecnológicos sejam utilizados como auxiliares no processo de evolução bumana (Diretrizes, 1997, p.03, grifos nossos).

Percebemos que, no discurso do governo, a instituição Escolar é responsável por proporcionar a melhoria da qualidade de vida de muitos jovens, a partir do acesso ao conhecimento. Nesse sentido, diminuir a lacuna existente entre a cultura escolar e o mundo ao seu redor, aproximar a escola da vida, torna-se tarefa das TICs e condição para o sucesso de uma política pública como o ProInfo. Ao defender que é preciso diminuir o espaço entre a escola e a sociedade, acaba-se parafraseando outro discurso: "aproximar a escola da vida". Vejamos que a nova ecologia é entrelaçar mentes humanas, as redes técnicas de armazenamento, transformação, produção e transformação de informações. Trata-se do discurso da cognição que objetiva desenvolver estruturas mentais

\footnotetext{
${ }^{5}$ De acordo com Orlandi, novamente se apresentam as soluções reformistas: cotas pra x, pra y, sem que se saiba muito bem qual é a prioridade: ser negro ou ser pobre? Ser negro é uma categoria social? Tem o mesmo peso de ser índio, no Brasil? Redução do social a categorias psicossociais, ou antropológicas, e não políticas e sociais em sua estrutura e funcionamento e que se prestam ao jogo e ao equívoco.
} 
mediadas pela cultura, linguagem e técnicas. Ou seja, é o discurso da enecatrônica: preparar robôs humanos para serem os novos cidadãos.

Assim, à Escola é dado o papel de preparar o novo cidadão, aquele que deverá colaborar na criação de um novo modelo de sociedade, em que os recursos tecnológicos sejam utilizados como auxiliares no processo de evolução bumana. Nessa formulação, observamos deslizes de sentido ao se apresentar outra categoria: novo cidadão, isto é, o cidadão do século XXI imerso em um mundo tecnologizado, rápido, mutável e dinâmico, auxiliando no processo de evolução humana. Para a Análise de Discurso, esses deslizamentos na linguagem se dão como efeitos metafóricos.

Através de deslizamentos de sentidos, de próximo em próximo, são totalmente distintos. No entanto, algo do mesmo está nesse diferente; pelo processo de produção de sentidos, necessariamente sujeito ao deslize, há sempre um possível "outro" mas que constitui o mesmo (ORLANDI, 2012, p.81, grifo da autora).

A metáfora está nesse novo sujeito: cidadão robô. Desse modo, por meio desses deslizamentos de sentidos, outros discursos se tornam possíveis, mas a discursividade, que sustenta a política de novos recursos tecnológicos como a inclusão digital, constrói um novo modelo de sujeito: mais dinâmico, conectado, evoluído, exatamente como proposto pela formação discursiva da evolução humana mediada pelas tecnologias.

Retomemos outro fragmento da entrevista:

[...] nós estamos distribuindo 60 mil portais digitais, para ter em tudo que é sala, e vão chegar a 78 mil, todas as salas de aula do Ensino Médio vão poder ter acesso ao portal e cada portal vai com um tablet de dez, polegadas, cada professor vai ter um tablet de sete polegadas. A diferença é só o tamanho, mas ele usa o que ele achar melhor. Ele preparou a aula dele, pesquisou, ele põe na memória do portal digital, para não ter risco, na bora, da banda larga não funcionar, mas ele trabalha, chega na sala de aula, ele apresenta a aula dele. Então, ao invés de ele ficar escrevendo no quadro negro, ele vai projetar um gráfico, vai projetar uma imagem. Ele vai dar uma aula de biologia, ele coloca o esqueleto, o corpo humano, os órgãos, a imagem real ou a imagem desenvolvida na internet. A aula fica muito mais criativa, fica mais rica. Ele vai dar uma aula de geografia, ele não precisa colocar o mapa. Ele entra no Google Maps e mostra qual é a região que ele está mostrando, ele entra no mapa e mostra, ele mostra o desenho, ele mostra informações muito mais sofisticadas. Então, a geração nova, ela quer essas informações, ela está exposta a essas informações. Não dá para a gente ficar só com o quadro negro do século XVII, século XVIII, para uma geração do século XXI. Então, a escola brasileira precisa se modernizar. [...] (Discurso do Ministro da Educação Aloízio Mercadante, grifos nossos).

As relações de trabalho existentes no mundo moderno do século XXI têm passado por grandes transformações desde a Revolução Industrial na Europa. A partir daí, tornou-se necessário estabelecer uma nova formação social e uma educação capaz de atender a esse novo contexto. A Escola, nesse aspecto, é uma ferramenta privilegiada para que isso se torne possível, pois, com as novas demandas sociais de mercado, exige-se uma nova categoria de trabalhador: o tecnologicamente competente.

No discurso do governo aqui representado pelo Ministro da Educação, podemos observar os sentidos produzidos sobre a Escola do século XXI, que, segundo ele, "não dá para a gente ficar só com o quadro negro do século XVII, século XVIII, para uma geração do século XXI. Então, a escola brasileira precisa se modernizar". Como vimos, a Escola é uma instituição poderosa de articulação das relações entre poder, conhecimento e tecnologias. Assim, o governo reconhece que a educação está atrasada, antiga. Novas tecnologias têm sentidos outros de modernização ao propor uma solução que é a de levar para a sala de aula essas novas ferramentas: trocam-se os quadros de giz pelos tablets educacionais. 
Há uma relação temporal entre passado, presente e futuro no discurso do Ministro, pois, para ele, a metodologia de ensino do século XVII já não mais é possível para o século XXI e, consequentemente, para os próximos anos que virão. Desse modo, por meio do uso do tablet, haverá de fato a modernização da educação e uma mudança bastante significativa na metodologia de ensino. Para o Ministro, se o professor "preparou a aula dele, pesquisou, ele põe na memória do portal digital, para não ter risco, na hora, da banda larga não funcionar, mas ele trabalha, chega na sala de aula, ele apresenta a aula dele. Então, ao invés de ele ficar escrevendo no quadro negro, ele vai projetar um gráfico, vai projetar uma imagem".

A posição discursiva na qual o Ministro da Educação se filia produz, como efeito de sentidos, o sujeito-professor: aquele que, ao ter contato com o tablet, já saberia construir uma aula usando todas as funções que essa ferramenta proporciona, ou já saberia usar todo o material disponível no portal do professor, deixando para trás as outras metodologias de ensino que funcionaram por anos na escola, tais como, o quadro negro e o livro didático.

No entanto, como se sabe, o problema não está apenas em substituir os modos de ensinar, mas também naquilo que se ensina. Sentidos que se filiam a uma memória discursiva que coloca em evidência que o modo como se ensina está pronto e disponível para todos, como se a política de uso de novas tecnologias não dependesse de uma construção de conhecimento, de preparo/qualificação. Desse modo, o uso do tablet, como solução tecnológica para a melhoria da qualidade de ensino, apaga a espessura do conhecimento e a das condições de produção dos professores.

\section{CONSIDERAÇÕES FINAIS}

Vimos ao longo desta pesquisa a maneira pela qual o Estado discursiviza o ProInfo e o Educação Digital nos arquivos que constituímos para análise, qual seja, no sentido da inclusão digital, da igualdade de direitos, da preparação do sujeito-aluno para o mercado de trabalho, enfim, na produção de uma discursividade do novo, isto é, o novo que está entrando no espaço escolar por meio das novas tecnologias digitais. Assim, na proposta do governo, as novas tecnologias são colocadas como possibilidade de melhoria da educação.

Compreendemos também que as políticas de formação continuada para professores não se deslocam das velhas práticas, pois a prática da capacitação continua a ser "um objeto na relação de trabalho. Agora bem treinado e, logo, mais produtivo" (ORLANDI, 2014a, p. 161). Ideologicamente esse é um dos interesses do Estado dominador, porque, com a capacitação e o treinamento, concebe-se o professor como um eterno repetidor, posto que não há apropriação de conhecimento por ele mesmo. Propor novas políticas de aprendizagem com base na inovação convoca uma nova concepção de professor, não sendo mais aquele a exercer um papel de transmissor de conhecimento, mas seu próprio produtor.

\section{REFERÊNCIAS BIBLIOGRÁFICAS}

ANDREOTTI, A. L. O projeto de ascensão social através da educação escolarizada na década de 1930. Disponível em: $<$ http://www.histedbr.fae.unicamp.br/navegando/periodo_era_vargas.html >. Acesso em: 18 de julho de 2015.

ARAÚJO, U. F. A quarta revolução educacional: a mudança de tempos, espaços e relações na escola a partir do uso de tecnologias e da inclusão social. Educação Temática Digital, Campinas, v.12, p.31-48, 2011. 
BARBOSA VAZ, Fabiana Andréa. Formação de Professores no Paraná: A Escola Normal Primária de Ponta Grossa (1924-1940). 2005. Dissertação (Mestrado em Educação) - Universidade Tuiuti do Paraná.

BRASIL. Ministério da Educação, Secretaria de Educação a Distância. - ProInfo. Programa Nacional de Informática na Educação. POPPOVIC, Pedro P. (Secretário de Educação a Distância) Brasília, 1997. [Doc. Eletrônico: http://www.proinfo.mec.gov.br/ (doc. original 11/mar/97).] Acesso em 14 de agosto de 2015.

BRASIL. Ministério da Educação e do Desporto. Portaria $\mathrm{n}^{\circ}$ 522, de 9 de abril de 1997.Disponívelem: http://www.dominiopublico.gov.br/pesquisa/PesquisaObraForm.jsp Acesso em 18 de março de 2015.

BRASIL. PRESIDÊNCIA DA REPÚBLICA. Decreto n6.300, de 12 de Dezembro de 2007. Dispõe sobre o Programa Nacional de Tecnologia Educacional - ProInfo. Decreto on-line. Disponível em: http://www.planalto.gov.br/ccivil_03/_Ato20072010/2007/Decreto/D6300.htm. Acesso em 20 de março de 2015.

BRASIL. Ministério da Educação e Cultura. Secretaria de Ensino Fundamental (SEF). Parâmetros Curriculares Nacionais. Brasília: MEC/SEF, 1998.

BRASIL. Constituição (1988). Constituição da República Federativa do Brasil. Brasília. DF: Senado, 1998.

BRASIL. Sistema nacional de educação: desafio para uma educação igualitária e federativa. Educação e Sociedade, Campinas, v.29, n.105, p.1187-1209, 2008.

DIAS. Cristiane Pereira. Telecentros como políticas públicas de inclusão digital: da administração da vida na cidade. In: ORLANDI, Eni Orlandi (Org.) A produção do consenso nas políticas públicas urbanas. Campina: Editora RG, 2010. p.43-73.

DI RENZO, Ana Maria. O Positivismo e a constituição da escola na República. In: MALUFSOUZA, O. et al. (Orgs.). Fronteiras discursivas: espaços de significação entre a linguagem, a história e a cultura. Campinas: Pontes, 2007. p. 25-37.

FERREIRA, Aurélio Buarque de Holanda. Míni Dicionário da Língua Portuguesa. $6^{a}$ Ed. Curitiba: Positivo, 2006.

FERNANDES, Claudemar Alves. Discurso e Sujeito em Michael Foucault. São Paulo: Intermeios, 2012.

NUNES, C. O "velho" "bom” ensino secundário: momentos decisivos. Revista Brasileira de Educação. n'.14, p.35-60, 2000.

ORLANDI, Eni Pulccinelli. Formação ou Capacitação? Duas formas de ligar sociedade e conhecimento. In: FERREIRA, Eliana Lucia; ORLANDI, Eni (Orgs.). Discursos sobre a inclusão. Niterói: Intertexto, 2014.

ORLANDI, Eni Pulccinelli. Interpretação, Autoria, Leitura e Efeitos do Trabalho Simbólico. $6^{a}$ Ed. Campinas: Pontes, 2012.

ORLANDI, Eni Pulccinelli. Formas de Individuação do Sujeito Feminino e Sociedade Contemporânea: $\mathrm{O}$ caso da delinquência. In: fabricação do consenso. Campinas, SP: Editora RG, 2010.

ORLANDI, Eni Pulccinelli. Discurso e leitura. 8 ed. São Paulo: Cortez, 2008. 
ORLANDI, Eni Pulccinelli. Língua e conhecimento linguístico: para uma história das ideias no Brasil. São Paulo: Cortez, 2002.

RIBEIRO, Manoel Pinto. Formações discursivas sobre a mulher na música popular brasileira, de 1930 a 1945. Niterói: Universidade Federal Fluminense, Tese de Doutorado, Curso de PósGraduação em Letras Universidade Federal Fluminense. 2007.

SILVA, Mariza Vieira da. História da alfabetização no Brasil: a constituição de sentidos e do sujeito da escolarização. Tese de doutorado Campinas, SP: UNICAMP. 1998.

SILVA, Mariza Vieira da. Sujeito, escrita e história: a letra e as letras. In: MARIANI, B. (Org.). A escrita e os escritos: reflexões em análise do discurso e psicanálise. São Carlos: Claraluz, 2006, p.133-140.

Recebido em 29/05/2017

Aceito em 12/09/2017

Publicado em 25/09/2017 